EESTI NSV TEADUSTE AKADEEMIA TOIMETISED. 19. KÖIDE KEEMIA * GEOLOOGIA. 1970, NR. 3

ИЗВЕСТИЯ АКАДЕМИИ НАУК ЭСТОНСКОН ССР. ТОМ 19 ХИмия * ГЕОЛОГИЯ. 1970, № 3

АЙНО ПИЛЛЬ

\title{
ВЛИЯНИЕ МОРСКОЙ ВОДЫ НА ХИМИЧЕСКИЙ СОСТАВ ВОДЫ РЕКИ ПЯРНУ В ЕЕ НИЖНЕМ ТЕЧЕНИИ
}

На гидрологический режим низовья рек, впадающих в морские за . ливы, значительное влияние оказывают колебания уровня воды последних. Кроме воздействия на уровень воды в реке наблюдаются также и изменения химического состава воды. Это влияние представляет интерес при выборе места водозабора речных вод, а также в связи с изучением влияния морской воды на химический состав подземных вод, находящихся под воздействием реки. В настоящей статье излагаются результаты исследований, произведенных в 1964-1965 гг. При этих исследованиях во время подъема и спада уровня, обусловленных нагоном и сгоном морской воды, отбирались пробы для химического анализа воды вдоль реки через каждые 0,5 км на протяжении примерно $10 \kappa м$ от устья (рис. 1).

Остановимся прежде всего на гидрологической характеристике и сгонно-нагонных явлениях в низовье р. Пярну.

По своей площади водосбора р. Пярну занимает третье место среди рек Эстонской ССР. Истоком реки принято считать родники Роозна-Аллику, выходящие на юго-западном склоне Паньдивереской возвышенности около 77 $\mu$

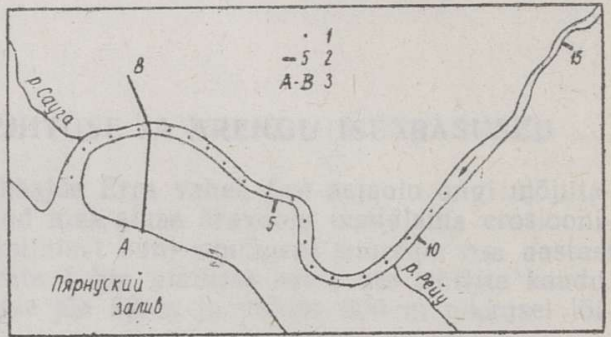

Рис. 1. Схематический план низовья р. Пярну:

1 - точки исследования; 2 - расстояние от устья, км; 3 - геологический разрез. над уровнем моря. Отсюда она течет в юго-западном направлении, впадая у г. Пярну в Пярнуский залив Балтийского моря. Площадь водосбора р. Пярну достигает $6910 \kappa \mu^{2}$, длина ее - $152 \kappa м$, ширина колеблется в среднем от 35 до $200 м$ (достигая местами 350 м), а глубина - от 1,5 до 7 м (Tiltsen, 1926; Основные гидрологические характеристики, 1966). В низовье р. Пярну течет в пределах Пярнуской низменности. Прорезая здесь четвертичные морские пески, она врезается в ленточные глины, образуя при этом довольно широкое $(100-350$ м) и глубокое $(3-7$ м) русло. Расход реки на створе, расположенном в 7 км от устья, в начале июля 1965 г. составил $47 \mathrm{~m}^{3} / с е \kappa$, а средняя скорость течения воды была равна 0,07-0,1 м/сек. Дно реки на рассматриваемом участке, располо- 
женном ниже уровня моря, неровное, полого понижающееся к ее устью (рис. 2). Пярнуский залив мелководный, углубляющийся в направлении открытого моря. Дно залива сложено ленточ-

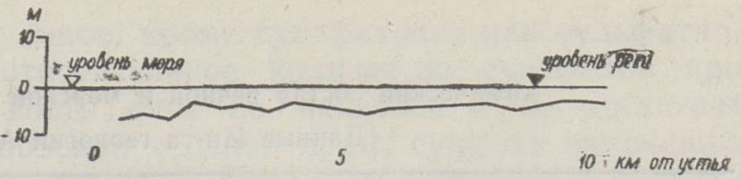

Рнс. 2. Схематический продольный профиль дна р. Пярну. ными глинами, перекрытыми около берега мелкозернистыми песками. Для защиты фарватера реки от наносов, построены два параллельных мола длиной около 2 км. Время от времени русло в устье реки на протяжении около $1,5 \kappa м$ подвергается искусственному углублению.

Поскольку низовье р. Пярну характеризуется весьма малыми уклонами водной поверхности $(0,0001)$ и неболышими скоростями течения воды, оно в значительной степени подвержено сгонно-нагонным процессам. Годовая амплитуда колебаний уровня реки достигает 205 см (Ocновные гидрологические характеристики, 1966), причем самые высокие урсвни отмечаются не во время половодья, а при нагонных явлениях. Наши исследования были произведены в марте и в июле, т. е. тогда, когда половодье не воздействовало на уровень реки. Интенсивность сгонно-нагонных колебаний уровня р. Пярну зависит от направления, силы и продолжительности ветров. Нагоны вызываются ветрами юго-западного н западного направления (со стороны моря), а сгоны - ветрами северовосточного направления (со стороны суши). Сгонно-нагонные явления в общем увеличиваются по мере усиления ветров (табл. 1): Однако кратковременный шквальный ветер может образовать только волнение, не вызывая подъема уровня воды в реке. В то же время менее сильные, но более продолжительные ветры могут дать значительный сгонный или натонный эффект (Алмазов, 1962).

Таблица 1

Изменение уровня воды реки под действием ветра на расстоянии 1 км от устья

\begin{tabular}{c|c|c}
\hline Дата & $\begin{array}{c}\text { Направление и скорость } \\
\text { ветра, м/сек }\end{array}$ & $\begin{array}{c}\text { Уровень над нулем } \\
\text { Кронштадтского } \\
\text { футштока, с.. }\end{array}$ \\
\hline
\end{tabular}

Июль 1964 г.:

$\begin{array}{lll}3 & Ю 3-7 & 16 \\ 4 & Ю 3-7-10 & 36 \\ 5 & Ю 3=4-8 & 30 \\ 6 & 13-9 & 32 \\ 7 & 3 Ю 3=8 & 42 \\ 8 & 3 Ю 3=10 & 46 \\ 9 & \text { Ю } & 28\end{array}$

При сильных и долговременных ветрах юго-западного или западного направлений нагон воды распространяется примерно на $12-13$ км от устья.

Солевой состав морских вод представлен преимущественно ионами хорошо растворимых хлоридов щелочных металлов, а в воде реки преобладают значительно менее растворимые карбонаты и сульфаты щелочно-земельных металлов (табл. 2). 
Химический состав речной и морской воды во время сгона (Данные Ин-та геологии АН ЭССР)

\begin{tabular}{|c|c|c|c|c|c|c|c|c|}
\hline \multirow{3}{*}{$\begin{array}{c}\text { Место отбора } \\
\text { проб }\end{array}$} & \multirow{3}{*}{$\begin{array}{c}\text { Минерали- } \\
\text { зация, } \\
\text { 2/л }\end{array}$} & \multirow{2}{*}{\multicolumn{7}{|c|}{$\frac{\mu 2 / \Omega}{\frac{\text { Состав В экв } \%}{}}$}} \\
\hline & & & & & & & & \\
\hline & & $\mathrm{Ca}$ * & $\mathrm{Mg} \cdot$ & $\mathrm{Na}+\mathrm{K} \cdot$ & $\mathrm{NH}_{4}$ & $\mathrm{HCO}_{3}^{\prime}$ & $\mathrm{SO}_{4}^{\prime \prime}$ & $\mathrm{Cl}^{\prime}$ \\
\hline $\begin{array}{l}\text { Река Плрну } \\
\text { (в } 9 \kappa M \text { от } \\
\text { устья) }\end{array}$ & 0,171 & $\frac{45}{72}$ & $\frac{10}{26}$ & $\frac{1}{1}$ & $\frac{0,7}{1}$ & $\frac{146}{76}$ & $\frac{18}{12}$ & $\frac{13}{12}$ \\
\hline $\begin{array}{l}\text { Пярнуский } \\
\text { залив }\end{array}$ & 5,028 & $\frac{86}{5}$ & $\frac{184}{18}$ & $\frac{1643}{77}$ & - & $\frac{183}{4}$ & $\frac{379}{9}$ & $\frac{2637}{87}$ \\
\hline
\end{tabular}

По химическому типу вода р. Пярну около гидрометеорологического поста Орекюла (в $26 \kappa м$ от устья реки) гидрокарбонатная магниевокальциевая. Минерализация воды колеблется от 0,1 (во время половодья) до 0,3 г/л (во время межени) * (Основные гидрологические харакгеристики, 1966). Приближаясь к устью, речная вода, как видно из табл. 3, обогащается ионами хлора и натрия.

Таблища 3

Химический состав речной воды по формуле Курлова во время сгона (Данные Ин-та геологии АН ЭССР)

\begin{tabular}{|c|c|c|}
\hline $\begin{array}{l}\text { Место отбора } \\
\text { проб }\end{array}$ & На поверхности & У дна \\
\hline $9 \kappa м$ от устья & $\mathrm{M}_{0,17} \frac{\mathrm{HCO}_{3} 76 \mathrm{SO}_{4} 12 \mathrm{Cl} 12}{\mathrm{Ca} 72 \mathrm{Mg} 26}$ & $\mathrm{M}_{0,17} \frac{\mathrm{HCO}_{3} 76 \mathrm{SO}_{4} 13 \mathrm{Cl} 11}{\mathrm{Ca} 70 \mathrm{Mg} 29}$ \\
\hline 6,5 & $\mathrm{M}_{0,18} \frac{\mathrm{HCO}_{3} 77 \mathrm{SO}_{4} 12 \mathrm{Cl} 12}{\mathrm{Ca} 66 \mathrm{Mg} 29}$ & $\mathrm{M}_{0,20} \frac{\mathrm{HCO}_{3} 70 \mathrm{Cl} 18 \mathrm{SO}_{4} 12}{\mathrm{Ca} 60 \mathrm{Mg} 26 \mathrm{Na} 13}$ \\
\hline 1,5 & $\mathrm{M}_{0,33} \frac{\mathrm{HCO}_{3} 73 \mathrm{Cl} 14 \mathrm{SO}_{4} 11}{\mathrm{Ca} 48 \mathrm{Mg} 45}$ & $M_{1,53} \frac{\mathrm{Cl} 86 \mathrm{HCO}_{3} 11}{\mathrm{Na61} \mathrm{Mg} 29 \mathrm{Ca} 10}$ \\
\hline у самого устья & $\mathrm{M}_{0,61} \frac{\mathrm{Cl} 166 \mathrm{HCO}_{3} 24 \mathrm{SO}_{4} 10}{\mathrm{Na} 55 \mathrm{Mg} 25 \mathrm{Ca} 19}$ & $\mathrm{M}_{4,30} \frac{\mathrm{Cl} 87}{\mathrm{~N} 75 \mathrm{Mg} 19}$ \\
\hline
\end{tabular}

При нагонах (ветры со стороны моря) морская вода, смешиваясь с речной водой, вызывает в ней ряд характерных изменений. Во-первых, повышается содержание хлоридов в воде вдоль реки (табл. 4). Во-вторых, в процессе нагона в речной воде изменяется соотношение концентрации отдельных ионов: повышается относительное содержание хлюра (от 10-15 до 80-85 экв.\%) и натрия (от $8-10$ до $75-80$ экв. \%), уменьшается содержание гидрокарбоната (от $75-80$ до $3-4$ экв. \%) и кальция (от $70-76$ до 5-6 экв.\%). Относительное содержание сульфатов остается по-прежнему в пределах 9-12 экв.\%. Минерализация воды увепичивается от 0,2 до 4,0 г/ $\Omega$. При этом химический тип воды меняется от гидрокарбонатного магниево-кальциевого до хлоридного натриевого при

* В данной статье в название типа воды включаются химические элементы при их содержании начиная с 20 экв.\%, порядок нанменований от меньшего к большему. Минерализация воды дается по. вычисленному сухому остатку. 
наличии всех промежуточных типов, кроме сульфатного или сульфатногидрокарбонатного, так как относительное количество сульфатов при смешении речной и морской воды почти не меняется и не достигает 20 экв. \%. Дальность проникновения соленой воды, судя по изменению количества хлоридов в водном потоке р. Пярну, относительно невелика (примерно 13 км от устья) и зависит от длительности нагона и скорости ветра (табл. 4).

Таблица 4

Изменение содержания хлоридов (в ма/л) при нагонах в поверхностных слоях речной воды вдоль р. Пярну

(Данные Ин-та экспериментальной и клинической медицины Мин. здравоохр. ЭССР)

\begin{tabular}{|c|c|c|c|c|c|c|c|}
\hline \multirow{2}{*}{$\begin{array}{l}\text { Дата } \\
\text { опробо- } \\
\text { вания }\end{array}$} & \multirow{2}{*}{$\begin{array}{c}\text { Продолжительность на- } \\
\text { гона перед опробова- } \\
\text { нием (в днях) }\end{array}$} & \multirow{2}{*}{$\begin{array}{l}\text { Скорость } \\
\text { ветра, } \\
\text { м/сек }\end{array}$} & \multicolumn{5}{|c|}{$\begin{array}{c}\text { Место опробования в км } \\
\text { от устья }\end{array}$} \\
\hline & & & 13,0 & 9,5 & 6,0 & 1,5 & 1,3 \\
\hline $\begin{array}{ll}8 / \mathrm{VII} & 1964 \\
16 / \mathrm{IX} & 1964 \\
19 / \mathrm{NII} & 1960\end{array}$ & $\begin{array}{l}6 \\
2 \\
0,5\end{array}$ & $\begin{array}{l}7-8 \\
8 \\
12\end{array}$ & $\begin{array}{l}28 \\
54 \\
-\end{array}$ & $\begin{array}{r}108 \\
95 \\
28\end{array}$ & $\begin{array}{l}418 \\
472 \\
490\end{array}$ & $\begin{array}{l}864 \\
708 \\
589\end{array}$ & $\frac{1323}{703}$ \\
\hline
\end{tabular}

Характерным является то, что во время нагонов происходит изменение химического состава речной воды не только вдоль реки, но и по ее глубине. Морская вода, как более плотная, сосредоточивается в придонных слоях (табл. 5).

Таблица 5

Изменение содержания хлоридов (в ме/л) в поверхностном и придонном слоях р. Пярну в зависимости от направления и силы ветров

(Данные Ин-та геологии АН ЭССР)

\begin{tabular}{|c|c|c|c|c|}
\hline \multirow{2}{*}{$\begin{array}{l}\text { Место отбора } \\
\text { проб }\end{array}$} & \multicolumn{2}{|c|}{$\begin{array}{c}17 / \mathrm{III} 1965 \\
\text { ветер } \mathrm{H} 3-7 \mathrm{~m} / \mathrm{ce \kappa}\end{array}$} & \multicolumn{2}{|c|}{$\begin{array}{c}25 / \mathrm{III} 1965 \\
\text { ветер ЮB }-5 \mathrm{~m} / \mathrm{ce \kappa}\end{array}$} \\
\hline & $\begin{array}{c}\text { поверхностный } \\
\text { слой }\end{array}$ & $\begin{array}{c}\text { придонный } \\
\text { слой }\end{array}$ & $\begin{array}{c}\text { поверхностный } \\
\text { слой }\end{array}$ & $\begin{array}{c}\text { придонный } \\
\text { слой }\end{array}$ \\
\hline $\begin{array}{ll}6,0 & \kappa \text { от } \text { устья } \\
5,0 & " \\
3,5 & " \\
2,5 & " \\
1,5 & " \\
1,0 & \text { У самого "устья }\end{array}$ & $\begin{array}{r}1 \overline{125} \\
158 \\
93 \\
930 \\
2272 \\
2343\end{array}$ & $\begin{array}{l}2301 \\
2472 \\
2436 \\
2510 \\
2431 \\
2502 \\
2567\end{array}$ & $\begin{array}{l}\overline{11} \\
21 \\
21 \\
50 \\
53 \\
53\end{array}$ & $\begin{array}{r}14 \\
14 \\
57 \\
43 \\
2298 \\
2283 \\
2316\end{array}$ \\
\hline
\end{tabular}

Таким образом нагон соленой морской воды распространяется вверх по течению реки, осолоняя главным образом ее придонные слои. Позже частичное перемешивание этих вод приводит к осолонению также поверхностных и к одновременному опреснению нижних слоев (Алмазов, 1962). Наблюдения показали, что наиболее соленая и плотная вода распространяется тонким слоем по дну реки, а верхние слои до глубины $2-3 м$, благодаря ветровому перемешиванию, более однородны по своей солености. Некоторое влияние на изменение солевого состава речной воды в низовье реки оказывают, по-видимому, и другие факторы, как например: испарение, атмосферные осадки и т. д., но по сравнению с нагонно-сгонными процессами значение этих факторов незначительное (Алмазов, 1962). 
Влияние моря при нагонах отражается не только на речной воде, но также и на подземных водах, изменяя пьезометрический уровень и хими ческий состав последних. Режимными наблюдениями подземных вод в районе р. Пярну установлена гидравлическая связь между речными и подземными водами. Так, колебания уровня подземных вод в наблюдательных скважинах, расположенных вблизи реки, хорошо отражают сгонно-нагонные колебания в низовье реки. Однако влияние колебания минерализаций солоноватой речной воды на колебания химического состава подземных вод зависит от геологического строения территории

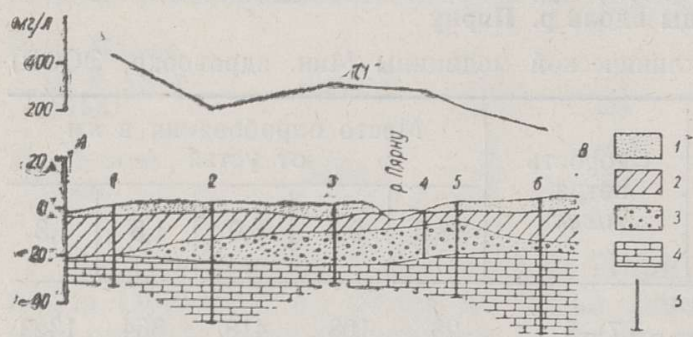

Рис. 3. Схематический геологический разрез г. Пярну с изменением содержания хлоридов в подземных водах верхнего силурийского водоносного горизонта:

1 - песок, 2 - водоупорные ленточные глины,

3 - гравий с песком, 4 - известняки и доломиты, 5 - скважина.

г. Пярну (рис. 3). Речная вода непосредственно связана только с грунтовыми водами морских песков. В наблюдательной скважине **, примерно в 10 м от правого берега реки и около 1,5 км от устья, минерализация грунтовых вод колеблется в больших пределах $(1,2-2,4 \quad 2 / \Omega)$ соответственно изменению содержания хлоридов и натрия в воде, а количество последних зависит от солености речной воды, т. е. от сгонно-нагонных процессов. Напорные воды первого от поверхности земли водоносного

горизонта, которые находятся в гранулометрически разнообразных четвертичных отложениях и которые гидравлически связаны с водами верхнего силурийского водоносного горизонта, отделены от поверхностных и грунтовых вод ленточными глинами мощностью в 4-18 м. Химический состав вод верхнего силурийского водоносного горизонта на площади г. Пярну неодинаковый. На рис. 3 видно, что содержание хлоридов увеличивается как в сторону моря, так и в направлении к берегу реки. Очевидно, несмотря на водоупор, солоноватая вода в пределах реки оказывает определенное влияние на химический состав вод верхнего силурийского водоносного горизонта. По данным исследования Әстонской гидрогеологической станции *** вода р. Пярну проникает в силурийский водоносный горизонт через неоднородные по составу ленточные глины, мощность которых в низовье равна только $3 м$ и которые возможно из-за нскусственного углубления русла местами совсем отсутствуют.

\section{ЛИТЕ РА Т У РА}

Алмаз ов А. М. 1962. Гидрохимия устьевых областей рек: Киев. Основные гидрологические характеристики. 1966. Сб. под ред. Т. Ф. Эйпре. 4, вып. 1, Л.

Tilt se n E. 1926. Pärnu jōgi ja tema veejōud. Tallinn.

Ннститут геологии

Академии наук Әстонской ССР
Поступила в редакцию 16/III 1970

** Л. А. Савицкий и др. 1969. Гидрогеологический ежегодник Эстонской гидрогеологической станции за 1968 год. Рукопись в фондах Упр. геол. СМ ЭССР.

*** Л. А. Савицкий, В. В. Кухар. 1964. Гидрогеологический ежегодник Эстонской гидрогеологической станции за 1963. Рукопись в фондах Упр. геол. СМ ЭССР. 
AINO PILL

\section{MEREVEE MÕJU JŌEVEE KEEMILISELE KOOSTISELE PÄRNU JŌE SUUDMEOSAS}

Merre suubuvate jōgede veerežiim ja jõevee keemiline koostis sõltuvad merepinna kõikumistest rannikul. Püüti välja selgitada, millist mõju avaldab selline veepinna kõikumine jōevee keemilisele koostisele Pärnu jõe suudmes ning kui kaugele see suudmest ulatub. Lääne- ja edelatuultega teatavasti tungib ajuvesi jõkke ja muudab jōevee taset, kuid ka keemilist koostist, kusjuures muutuste ulatus sõltub tuule tugevusest ja kestusest. Sedastati, et ajuvee puhul rikastub jōevesi kloriidide ja naatriumiga, väheneb vesinikkarbonaadi ja kaltsiumi suhteline hulk, sulfaatidesisaldus aga jääb endiselt 9-12 ekv.-\% piiridesse. Mineralisatsioon tõuseb kuni $4 \mathrm{~g} / \mathrm{l}$. Merevesi kui erikaalult raskem vajub alla ja liigub ajuvee puhul älesvoolu mööda jōe põhja ōhukese kihina. Liikumisel vesi seguneb, toimub ïlemiste kihtide soolastumine ja alumiste kihtide magestumine. Vee keemiline koostis aga ei ühtlustu: ülemised veekihid $2-3 \mathrm{~m}$ sügavuseni jäävad alumistest tunduvalt magedamaks.

Merepinna kõrgseisu ajal filtreerub soolastunud jõevesi teataval määral ümbritsevaisse kivimeisse ja mõjutab omakorda jõe suudmealal pinnase- ja põhjavee keemilist koostist.

\section{AINO PILL}

\section{DIE EINWIRKUNG DES SEEWASSERS AUF DIE CHEMISCHE ZUSAMMENSETZUNG DES FLUSSWASSERS IM MÜNDUNGSGEBIET DES PÄRNU-FLUSSES}

Das Regime und die chemische Zusammensetzung des Wassers der in die See mündenden Flüsse hängt von den Niveauschwankungen des ufernahen Seewassers ab. Durch Untersuchungen im Mündungsgebiet des Pärnu-Flusses versucht der Verfasser, den Einfluß herauszuklären, den solche Niveauschwankungen auf die chemische Zusammensetzung des Flußwassers ausüben, und wie weit diese Einwirkung flußaufwärts reicht. Die Westand Südwestwinde drängen die Meeresflut in das Flußbett. Die dadurch bedingten Unterschiede im Niveau und in der chemischen Zusammensetzung sind von der Windstärke und von der Dauer des Windes abhängig. Dabei wird das Flußwasser reicher an Chloriden urid an Natrium. Die relative Menge der Hydrokarbonate und des Kalziums hingegen nimmt ab, während der prozentuelle Gehalt an Sulfaten nach wie vor in den Grenzen vou 9-12 äqu. \% bleibt. Die Mineralisation steigt bis $4 \mathrm{~g} / 1$. Das Seewasser - es ist das dichtere - sinkt niedriger und dringt bei derartiger Meeresflut als dünne Schicht am Grunde entlang flußaufwärts. Es erfolgt seine Vermischung mit dem Flußwasser, wobei die oberen Schichten salziger, die unteren weniger salzig werden, doch ohne dab die chemische Zusammensetzung einheitlich wird. Die oberen Schichten bleiben bis zu einer Tiefe von $2-3 \mathrm{~m}$ bedeutend weniger salzhaltig als die unteren.

Das während der Meeresflut salziger gewordene Flußwasser infiltriert sich bis zu einem gewissen Grad in die Gesteine des Flußbettes und wirkt so wiederum auf die chemische Zusammensetzung des Grundwassers und des bodennahen Wassers ein. 